\title{
Plexiform neurofibroma of the upper limb
}

\author{
Neurofibroma plexiforme de membro superior
}

\begin{tabular}{r} 
Kátia Torres Batista ${ }^{1}$ \\
Hugo José de Araújo \\
Aloysio Campos da PAZ \\
JÚNiOR $^{2}$ \\
\hline Study conducted at SARAH \\
Network of Rehabilitation \\
Hospitals, Brasília, DF, Brazil. \\
Submitted to SGP (Sistema de \\
Gestão de Publicações/Manager \\
Publications System) of RBCP \\
(Revista Brasileira de Cirurgia \\
Plástica/Brazilian Journal of \\
Plastic Surgery). \\
Received: October 16, 2009 \\
Accepted: April 6, 2010
\end{tabular}

\section{INTRODUCTION}

Neurofibromas, tumors that originate in Schwann cells and normally show the clinical symptoms of type 1 neurofibromatosis (NF1), are rarely found in the hands.

A diagnosis of NF1 is considered if two of the following characteristics are present:

- six or more light brown stains with a diameter of $>0.5 \mathrm{~cm}$ in prepubertal and $>1.5 \mathrm{~cm}$ in postpubertal individuals;

- two or more neurofibromas of any type or one plexiform neurofibroma (net shaped);

- ephelides in the axillary or groin area;

- optic glioma (tumor in the optic nerve);

- two or more Lisch nodules in the iris;

- sphenoid dysplasia or thinning of the cortex of long bones, with or without pseudoarthrosis;

- first-degree relative with NF1;

- biopsy findings ${ }^{1-3}$.

Neurofibromas are benign tumors, usually single and originating within the nerve fascicles. Enucleation is not possible, so total tumor excision is required, leaving some damage to hand function. Surgery is indicated in cases of excessive tumor growth, pain, and when there is suspicion of malignancy ${ }^{4}$.
This paper aims to describe the evolution of a case of upper limb plexiform neurofibroma in a patient with NF1.

\section{CASE REPORT}

A 3-year-old female child was admitted to the unit of SARAH Network of Rehabilitation Hospitals in Brasília (SARAH-Brasília, Brazil) in 1996 with a history of left wrist tumor measuring $2 \mathrm{~cm} \times 3 \mathrm{~cm}$, diagnosed as neurofibroma. NF1 was diagnosed on the basis of the following criteria: family history and presence of light brown stains, neurofibromas, and plexiform neurofibroma.

In 2004, the patient developed a tumor and dysfunction due to pain in the upper limb, sensory changes, and an inability to clamp the thumb with the fifth finger. Physical-functional assessment of the left arm showed the following characteristics: swelling in the forearm and palmar region; loss of protective sensitivity in the second and third fingers and in part of the palmar and dorsal regions of the hand; loss of protective sensitivity of the distal phalanges of the second and third fingers and middle phalanx of third finger; difficulty in performing spherical grip, cylindrical grip, and clamping functions of the thumb

1. Member of the Brazilian Society of Plastic Surgery; Physician; Plastic Surgeon of SARAH Network of Rehabilitation Hospitals, Brasília, DF, Brazil.

2. Doctor of Orthopedics; Surgeon-in-Chief of SARAH Network of Rehabilitation Hospitals, Brasília, DF, Brazil. 
with the second and fifth fingers; preserved hook grip; preserved joint mobility and strength; and neurofibromas distributed bilaterally in the brachial plexus and in other peripheral nerves of the upper limbs. Moreover, there was evidence of a bulky mass in the pelvic region; this mass was pushing against the structures of the bladder and rectosigmoid region and extending along the lower limb and gluteal region, corresponding to the lumbosacral plexus. The patient did not have functional complaints related to these tumors.

The patient underwent electromyography tests (Figure 1) and MRI in sagittal, coronal, and axial sections. These tests revealed elongated cylindrical structures, grouped into a bulky expansive injury, from the anteromedial face of the arm and forearm to the palmar face of the hand and passing through the carpal tunnel.

A tumor (size, $23 \mathrm{~cm} \mathrm{x} 4 \mathrm{~cm}$; weight, $172 \mathrm{~g}$ ) located in the left upper limb was resected (Figures 2 to 5). Histopathological evaluation of frozen tissue sections led to a diagnosis of neurofibroma of the median nerve.

The patient recovered with improvement in hand function and relief from pain symptoms. The patient retained clamping movements of the thumb with the other digits (Figures 6 to 10) and object gripping, and the sensitivity

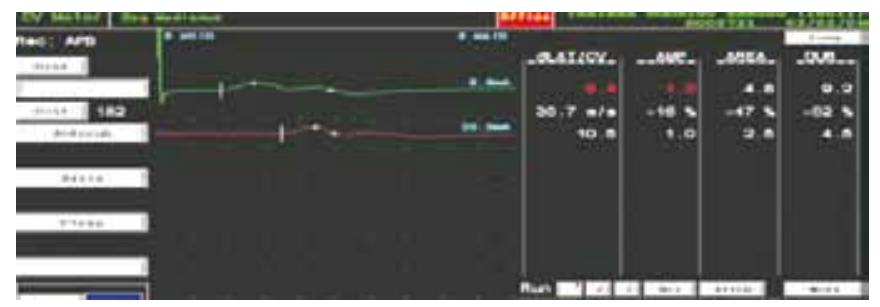

Figure 1 - Results of the electromyographic test, showing marked reduction in the extent and speed in the motor conduction study.

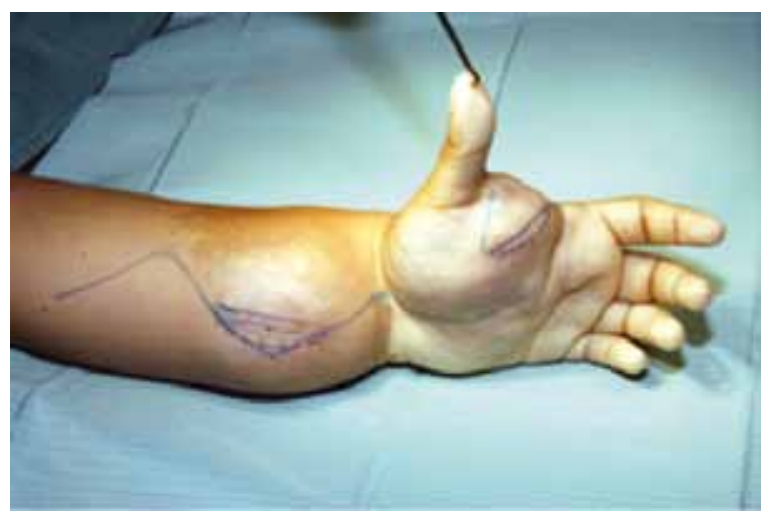

Figure 2-Marking held at the immediate preoperative period of patient with plexiform neurofibroma of the left upper limb. map, measured using Semmes-Weinstein monofilaments, remained unchanged. Finally, there was no evidence of tumor recurrence in the operated area for four years.

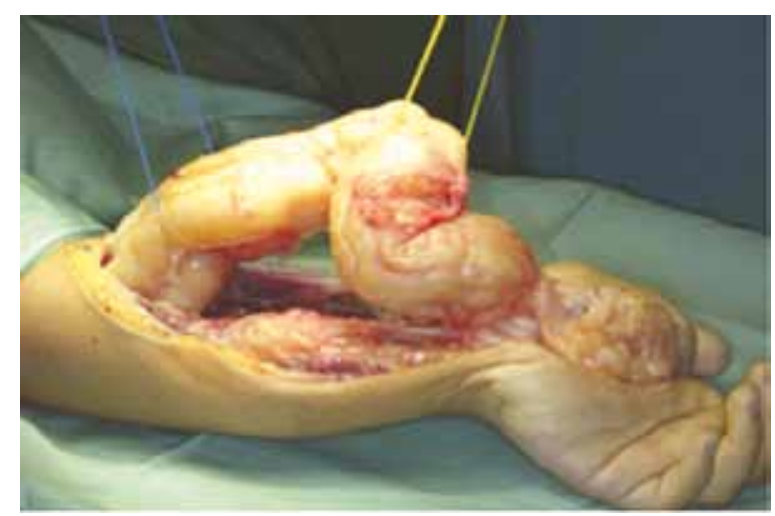

Figure 3 -Dissection of the tumor on the left median nerve.

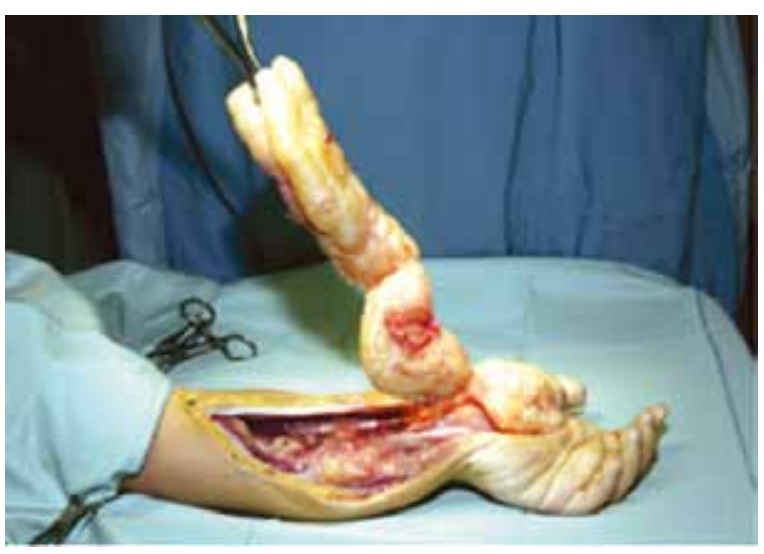

Figure 4-Resection of the tumor on the left median nerve.

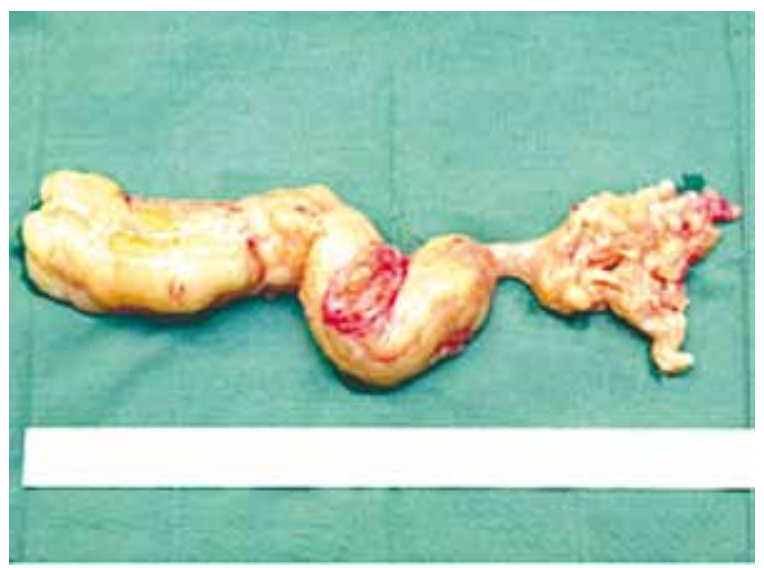

Figure 5 -After resection of tumor on the median nerve. 


\section{DISCUSSION}

Neurofibromas may occur anywhere in the body and viscera, and rarely occur in the hands. Some authors ${ }^{1,2}$ have reported an incidence of $0.8 \%$ for neurofibromas in the hands and from $10 \%$ to $15 \%$ for NF1.

Plexiform neurofibromas show diffuse growth of the endoneurium, affecting all branches of the nerve, as demonstrated in this case of tumor of the median nerve and its branches, with severe constriction of the carpal tunnel ${ }^{3-5}$. Plexiform neurofibromas are considered difficult to diagnose because their incidence is very low ${ }^{6}$, but when the criteria of neurofibromatosis ${ }^{7}$ are fulfilled, the suspicion of plexiform neurofibroma increases. However, clinicians should carry out differential diagnoses for other neural tumors, such as schwannoma ${ }^{8}$ and sarcomatous degeneration ${ }^{2}$.

The surgical treatment of neurofibromas is controversial, since it is necessary to excise the entire nerve for tumor removal.

According to Seddon ${ }^{4}$, tumor resection is not necessary, unless the tumor causes pain, shows exuberant growth, or impairs

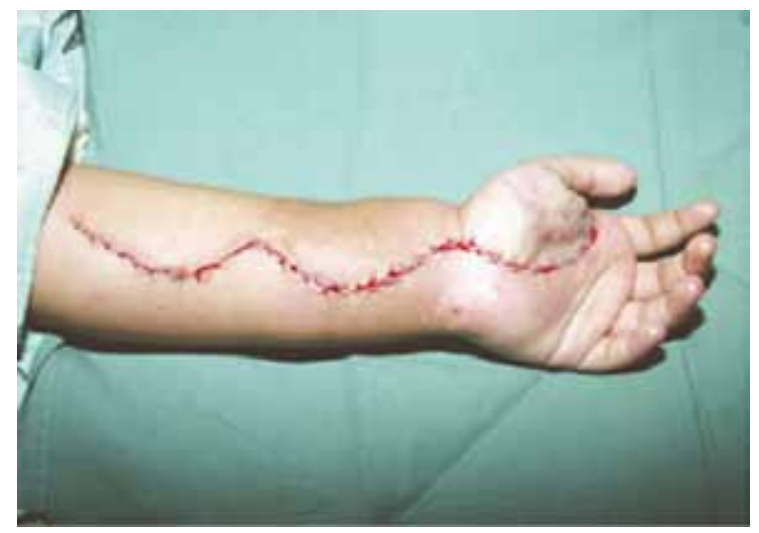

Figure 6-Closing of the surgical wound.

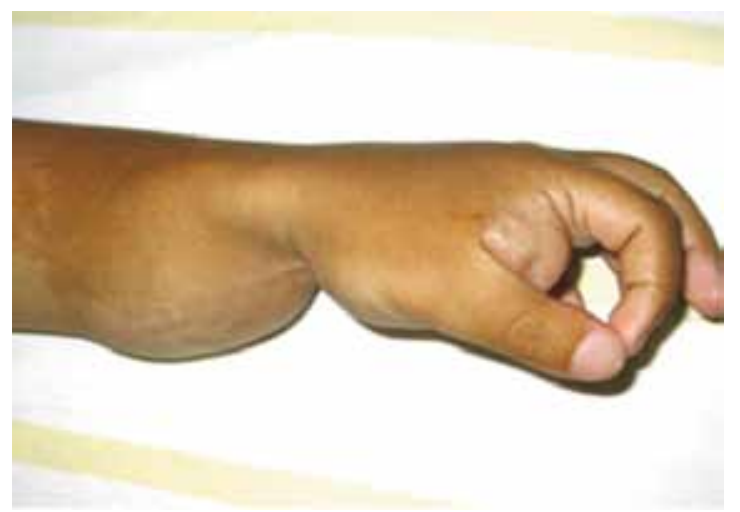

Figure 7 - Thumb clamping movement with the second finger, observed during the preoperative period. function, as in this case. The evolution of neurofibromatosis with neurofibroma as a slow, asymptomatic growth over eight years has been reported. Surgery was indicated because of hand dysfunction and pain due to tumor growth. It was possible to remove the

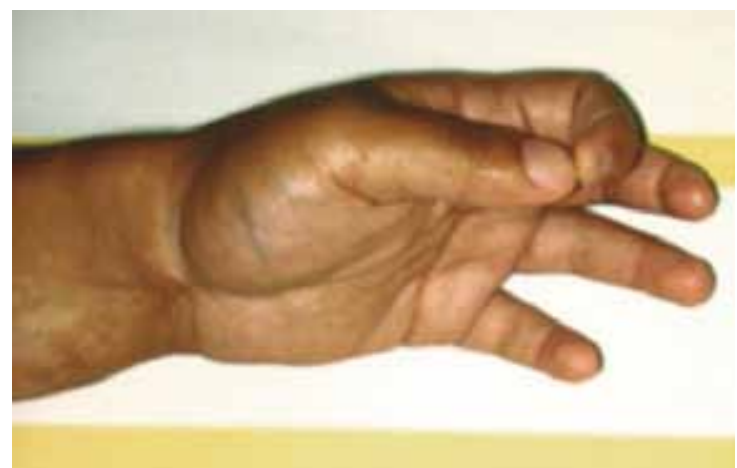

Figure 8 -Maintenance of clamping movement after the sixth month of tumor resection.

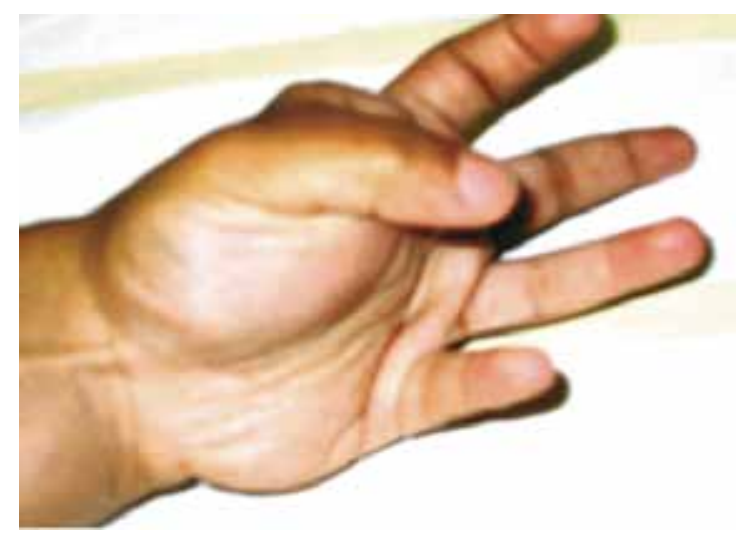

Figure 9 - Failure to perform a clamping movement of the thumb with the fifth left finger, observed in the preoperative period.

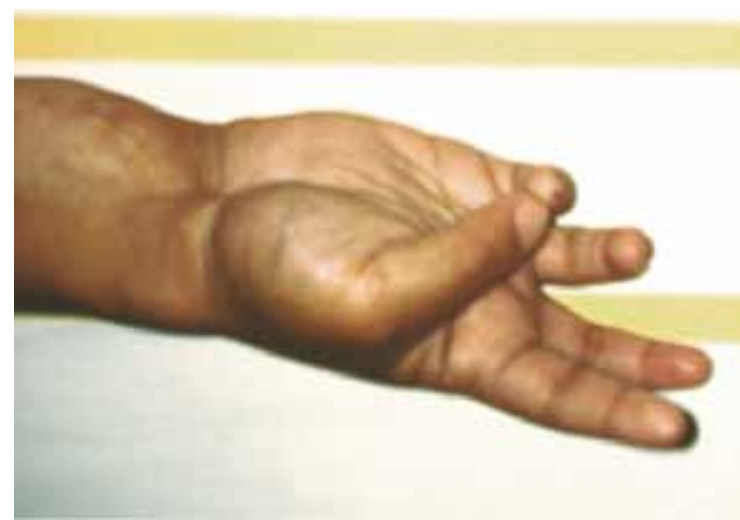

Figure 10-Recovery of the clamping movement of the thumb with the fifth finger, observed in the postoperative period. 
plexiform neurofibroma of the median nerve; the symptoms of pain reduced and hand function improved over a follow-up period of four years, with no signs of recurrence of this tumor.

\section{REFERENCES}

1. Basheer H, Rabia F, Basheer H, el-Helw K. Neurofibromas of digital nerves. J Hand Surg Br. 1997;22(1):61-3.

2. Birch R. Peripheral nerve tumors. In: Dyck PJ, Thomas PK, eds. Peripheral neuropathy. $3^{\text {rd }}$ ed. Philadelphia: WB Saunders; 1993. p. 1623-39.

3. Nambi GI, Gupta AK, Kumaran S. Plexiform neurofibroma of the finger. J Plast Reconstr Aesthet Surg. 2008;61(11):1402-3.
4. Seddon HJ. Surgical disorders of peripheral nerves. Baltimore: Williams and Wilkins; 1972.

5. Punia RS, Dhingra N, Mohan H. Cutaneous plexiform schwannoma of the finger not associated with neurofibromatosis. Am J Clin Dermatol. 2008;9(2):129-31.

6. Ilyas AM, Nourissat G, Jupiter JB. Segmental neurofibromatosis of the hand and upper extremity: a case report. J Hand Surg Am. 2007;32(10):1538-42.

7. Gajeski BL, Kettner NW, Awwad EE, Boesch RJ. Neurofibromatosis type I: clinical and imaging features of Von Recklinghausen's disease. J Manipulative Physiol Ther. 2003;26(2):116-27.

8. Westhout FD, Mathews M, Pare LS, Armstrong WB, Tully P, Linskey ME. Recognizing schwannomatosis and distinguishing it from neurofibromatosis type 1 or 2. J Spinal Disord Tech. 2007;20(4):329-32.

\section{Correspondence to:}

Kátia Torres Batista

SMHS - Quadra 501 - cj. A - Brasília, DF, Brazil - CEP 70335-901

E-mail:katiatb@terra.com.br 